ISSN 2766-2624

\title{
Moving and Fixed Biological Biofilm Systems in Wastewater Treatment- when dose an Application Makes Sense
}

\author{
Advances in Earth and Environmental Science
}

Research Article

\author{
Noama Shareef $^{1^{*}}$ and Rifaat Abdel Wahaab ${ }^{2}$
}

${ }^{1}$ International Center for Migration and Developing, Germany

*Correspondence authors

${ }^{2}$ Holding Co. for Water \& Wastewater (HCWW), Cairo, Egypt

\author{
Noama Shareef \\ International Center for Migration and Developing \\ Germany
}

Submitted : 16 Jun 2021 ; Published : 30 Jun 2021

\begin{abstract}
This study demonstrates the optimization of different Biofilm applications in wastewater treatment for a costeffective solution. The increase of wastewater treatment cost because of high treatment efficiency requested and energy consumption makes such applications very interested in this field. Therefore, aerated reactors for wastewater treatment units were designed to work as Submerged Fixed Biofilm Bed, on the basis of biofilm-microorganisms attached to monolithic plastic supports to increase the treatment efficiency. This application depends on the aerobic process and achieved by the aeration in BOD reduction and Nitrifications reactors (Oxidation of organic compounds and nitrification). This was implemented by mixing and transport treatment processes within the biofilm attached to the plastic fixed media. The anaerobic reactor in this study was designed also to be simultaneous the de-nitrification stage by the application of a moving bed de-nitrification reactor which was considered as a part of the wastewater treatment process to achieve high treatment efficiency for the study pilot plant.
\end{abstract}

The one-year-scientific evaluation was conducted onsite for the municipal wastewater pilot plant includes a test series with well-defined treatment parameters (soft mixing of the suspending the moving bed carriers; intermediate solids removal unit prior to the nitrification reactors; the mechanism for preventing the carriers to move with the flow into the subsequent reactor) such as waste-water-flow, quality, temperature, salinity, organic and hydraulic load and extensive sampling). The above application of the compact-container-system is considered as a typical field of application, for the following reasons:

- Need of quality improvements discharged into water body, which is often in the vicinity of bathing beaches;

- Need for Nutrient-Removal-Systems to avoid algae growth going into water bodies and;

- $\quad$ Space limitations in a resort and saving the implementation capital cost).

The comparison between the application of the biofilm concept and the activated sludge system saved more than $40 \%$ tank size; $85 \%$ space/area; and up to 30\% construction cost.

Keywords: Biofilm Treatment Technologies; Moving bed, Submerged Fixed-bed, hybrid-reactor, compact-container-system

\section{Introduction}

Biofilm systems are used widely to develop wastewater treatment technologies and increase the efficiency wastewater treatment and decrease of energy consumption in many applications as cost-effective solutions [1,2]. Different fixed growth biofilm reactors are commercially used for the treatment of municipal as well as industrial wastewater. Therefore, the awareness of biofilms has increased enormously in recent years due to the impact of biofilms on natural and industrial systems, as well as human health. Biofilm processes require less space as they keep consistently the active sludge concentration in the biological reactor at a high level [3]. Biofilm processes do not need sludge recirculation thus making the biological treatment process independent from sedimentation tank performance and sludge characteristics. This is especially of great importance for applications where the type of waste implies the risk of high sludge volume indices (MSU 2000). The increase of the demands on efficiency and cost of wastewater treatment leads to new interest in biofilm technology which leads to an important positive impact that can affect the treatment cost, operation, and treatment efficiency in several countries in the region. The analysis of the incremental scenarios have shown that the change in precipitation and the temperature will highly affect the amounts of monthly surface runoff and the mean annual temperature increased by $1,2,3$, and $4 \mathrm{C}^{\circ}[4]$.

Several Biofilm-Fixed films were types of fixed-film bioreactors that were developed nearly 100 years ago (Logan et al., 1987). In a biofilm, filter microorganisms grow on a solid

Adv Earth \& Env Sci; $2021 \quad$ www.unisciencepub.com Volume 2| Issue 2 
packing material forming a biofilm. As the wastewater flows through this packing material the microorganisms will degrade the organic compounds and nitrification in the wastewater according to the method described by $[5,6]$.

As more microorganisms are attached to the material and as they grow the biofilm gets thicker. Eventually, the biofilm will be so thick that the microorganisms will gradually lose their ability to cling to the packing material and the biofilm will be washed off. This is a process called sloughing [7]. The biofilm will start to grow on the packing material surface as the packing material is an underdrain system that not only collects the treated effluent but also provides a porous structure through which air can flow providing oxygen to the microorganisms [8].

In most cases, the influent wastewater has to undergo mechanical cleaning and primary sedimentation before it can be flows into the filter to avoid problems with clogging. Many applications of Biofilm technologies have been successfully applied as a low-cost treatment technology in the Arid Region and shows a high treatment efficiency in it applications for small and large scales of waterwater treatment plants [9].
The aim of this study is to test this new concept on a pilot scale with a capacity of $200 \mathrm{PE}$ and evaluate of the treatment efficiency of the adequate hybrid-reactor-container-plant by optimizing the moving bed and submerged fixed-film applications serving scientific purposes and full-scale applications respectively. Furthermore, certain novel elements of the applications and operations processes were tested.

\section{Materials and Methods}

Site description

The pilot plant based on a combination of an aerated submerged fixed bed biofilm and an anoxic moving bed de-nitrification reactor for a concept on a pilot scale with a capacity of $200 \mathrm{PE}$. It is located about $50 \mathrm{~km}$ south of Tunis. Figure 1 shows the layout of the wastewater treatment pilot plant.

The System consists of two containers, placed side by side with an upstairs walkway amid. The first container embodies the de-nitrification reactor (with the screen mounted atop), the C-removal reactor, the intermediate settling and room for pump- and control units. The second container embodies the nitrification reactor (separated into three compartments), the final settling tank and two GRP tanks for sludge thickening and Aerobic-Thermophilic treatment. The entire system is developed for easy on-site-assembly.

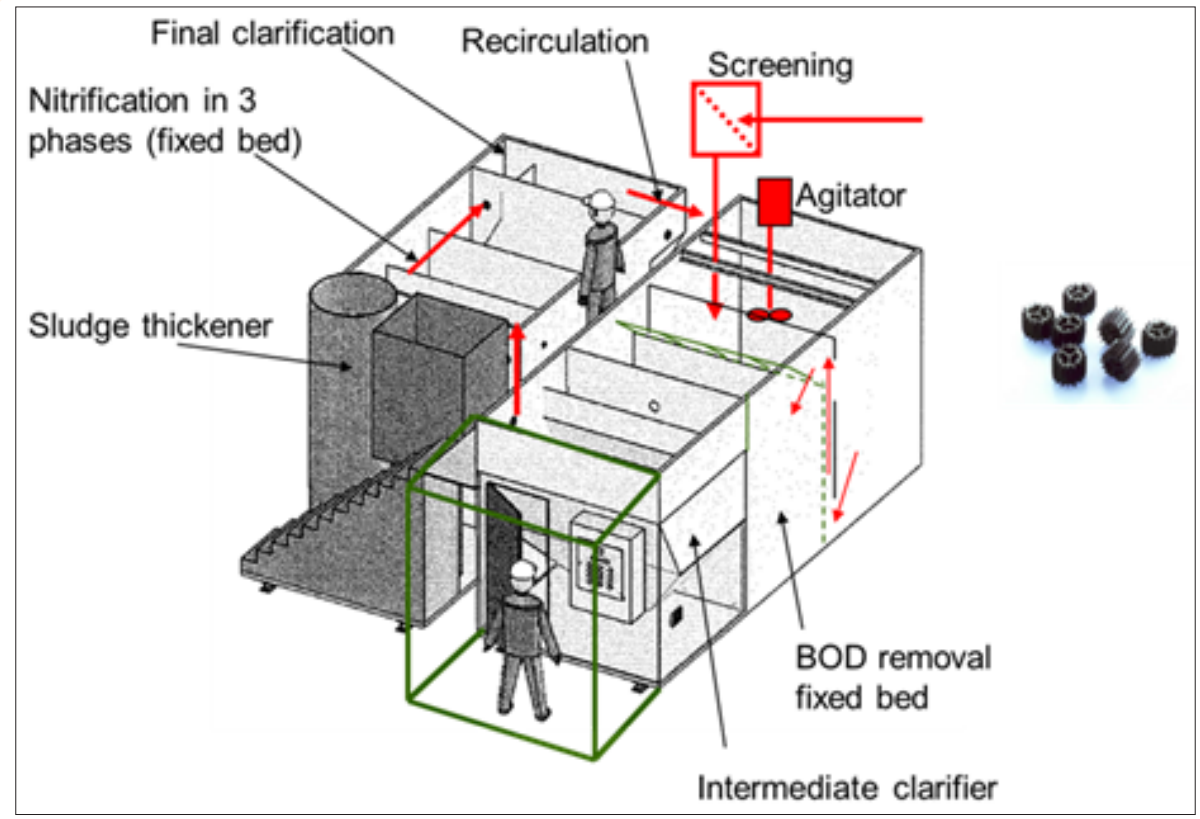

Figure 1: layout of the compact, wastewater treatment pilot unit of $200 \mathrm{PE}$

Field measurements were conducted directly after sampling from several points (inflow, outlet of the pilot for the parameters: $\mathrm{EC}, \mathrm{pH}$ and temperature after [10]. Subsequently, NH4+ - N, NO2-N, NO3-N, analyses. COD, TN, NH4-N, TP, and PO4, TP, TN, BOD5, TSS, Turbidity, and Microbial Analysis E. coli were analysed weekly onsite and locally.

\section{Material Specification}

The plastic foils for the bio-filter media are produced using the patented $2 \mathrm{H}$ Kunststoff $\mathrm{GmbH}$ system for extruding the Polypropylene polymer and directly forming the molten mass into the corrugated foils. The polypropylene polymer material shall be specially formulated for optimum UV stability according to the factory of the $2 \mathrm{H}$ Kunststoff $\mathrm{GmbH}$ in Germany. This continuous extrusion process produces the foils directly from the molten polymer material and this ensures that the "plastic memory" is as a corrugated sheet unlike foils that are vacuum formed from the pre-calendared flat sheet where under heat stress, the material tries to revert to its flat form.

The structured growth-media is balanced out for maximum surface depends on the inflow wastewater organic load and 
other design factors [11].This will be ensure that the filer works in its full capacity also it minimizes the risk of clogging or increasing the treatment capacity of the filter media which can be caused by bad primary treatment $[12,13]$. Therfer, the arrangement results in fast acting bacteria and rapid pollutant removal.

\section{Operation}

The pilot plant is designed to treat municipal wastewater capacity of $200 \mathrm{PE}$ with a Specific wastewater load of 20-40 $\mathrm{m} 3 / \mathrm{d}$ and BOD5 load as a daily average of $20 \mathrm{~kg} / \mathrm{d}$. This pilot plant based on a combination of an aerated submerged fixed bed biofilm (SFBB) and an anoxic moving bed denitrification
(MBDR) reactor. The study also aimed to test this new concept on a pilot scale with a municipal wastewater type in the MENA region. Table 1 is listing the designed parameters regarding the expected biological turn-over rates. After all, the projected plant provides some excess capacity. This application was designed to produce treated wastewater quality of BOD $5 \leq 10 \mathrm{mg} / 1$; COD $\leq 100 \mathrm{mg} / \mathrm{l} ; \mathrm{TSS} \leq 25 \mathrm{mg} / \mathrm{l} ; \mathrm{NH} 4 \leq 2 \mathrm{mgN} / 1 ; \mathrm{NO} 3 \leq 10 \mathrm{mg} / \mathrm{l}$. It was tested for wastewater with nitrogen input concentrations of $100 \mathrm{mg} / \mathrm{l}$ and higher as it is frequent in arid countries. The application of this concept makes sure that the reliable operation of the plant does not need experienced personnel. Figure 2 shows the flow displays scheme of the treatment plant by using specific design of plastic media.

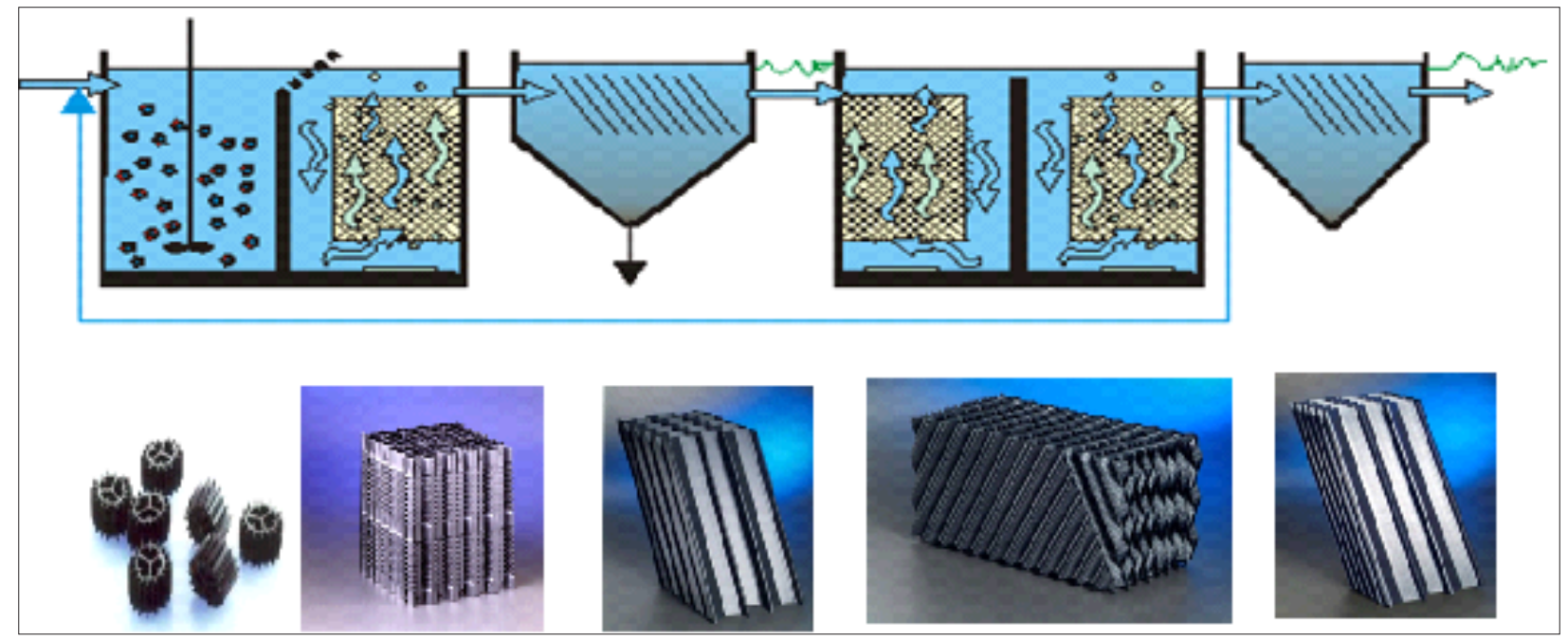

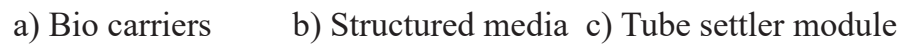

d) Structured media e) Tube settler geometry

Figure 2: components applied in the experimental WWTP concept of (2H Kunststoff GmbH); Application of Bio carries media filter in denitrification, structured media in Nitrification and Tube Steller in sedimentation reactors

\begin{tabular}{|l|l|l|l|l|}
\hline \multirow{2}{*}{ Item/Unit } & gBOD $/ \mathrm{m}^{2} / \mathrm{d}$ & gNO3-N $/ \mathrm{m}^{2} / \mathrm{d}$ & $\mathrm{gNH} 4-\mathrm{N} / \mathrm{m}^{2} / \mathrm{d}$ & Applied surface \\
\cline { 2 - 5 } & Max. flow $\left(\mathrm{m}^{3} / \mathrm{h}\right)$ & tube volume $\left(\mathrm{m}^{3}\right)$ & proj. Surface $\left(\mathrm{m}^{2}\right)$ & surface load $\left(\mathrm{m}^{3} / \mathrm{m}^{2} / \mathrm{h}\right)$ \\
\hline Denitrification & 3.5 & 1.0 & -- & $834 \mathrm{~m}^{2}$ \\
\hline C-Removal & 9.0 & -- & -- & $770 \mathrm{~m}^{2}$ \\
\hline Nitrification & -- & -- & 1.2 & $2082 \mathrm{~m}^{2}$ \\
\hline $\begin{array}{l}\text { Intermediate } \\
\text { settling }\end{array}$ & 7.6 & 2.53 & 13.7 & 0.55 \\
\hline Final settling & 2.1 & 0.76 & 6.6 & 0.32 \\
\hline
\end{tabular}

Table 1: Design parameter of the treatement unit

\section{Results and Discussion}

The efficiency of each subsequent step depends on the performance of the previous step. The compact system using Submerged Fixed Film for nitrification stage and moving bed for the denitrification stage is implemented as a tailormade design to favor the growth of specialized bacteria. The specialized bacteria is kept on its place and supplied with its individual needs of oxygen and nutrients.

Results showes that; halving the hydraulick loads of inflow wastewater inflow does not have any effect on mining treatment performance in the load case of this study.
During the starting of the operation time, the COD degrad $>$ $80 \%$, NH4-N degradation almost $100 \%$, and low COD degradation after changing the operating system ( Figure 3).

Also during the first operation phase, a high reduction in both TOC and N-Total was obtained. The results ulstrated in Figure (4) shows a high treatment efficiency in final outlet (BOD5 $\leq 10$ $\mathrm{mg} / \mathrm{l}, \mathrm{COD} \leq 100 \mathrm{mg} / \mathrm{l}, \mathrm{TSS}: \leq 25 \mathrm{mg} / \mathrm{l}, \mathrm{NH} 4-: \leq 2 \mathrm{mgN} / \mathrm{l}$, $\mathrm{NO} 3 \leq 10 \mathrm{mgN} / \mathrm{l})$.

It is worth to highlight that biofilm application scenario using submerged fixed-film for the aerobic reactor and moving bed for anaerobic denitrification stage proved high treatment performance and secured the treatment efficiency (Figures 5-9) 


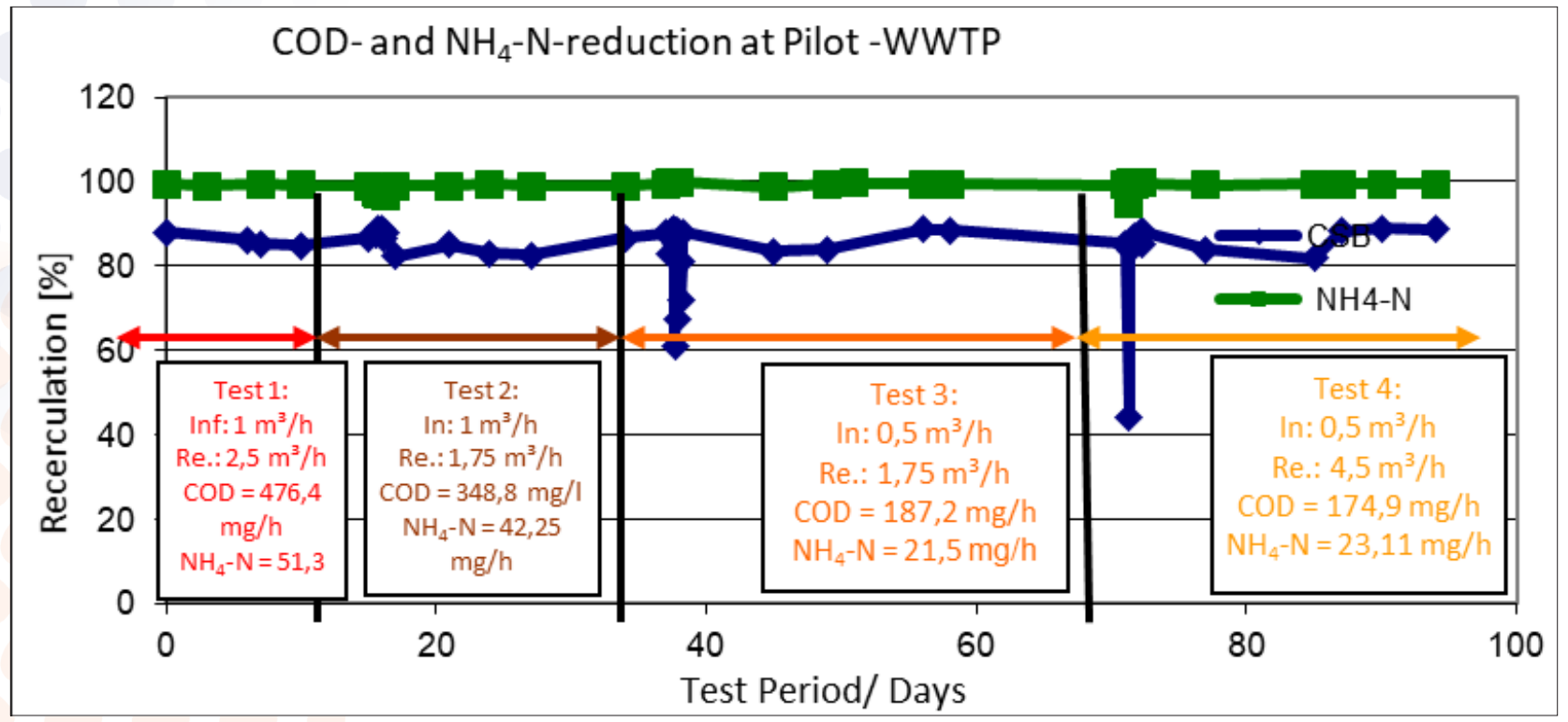

Figure 3: COD- and NH4-N reduction at the Pilot Plant during the operation phase

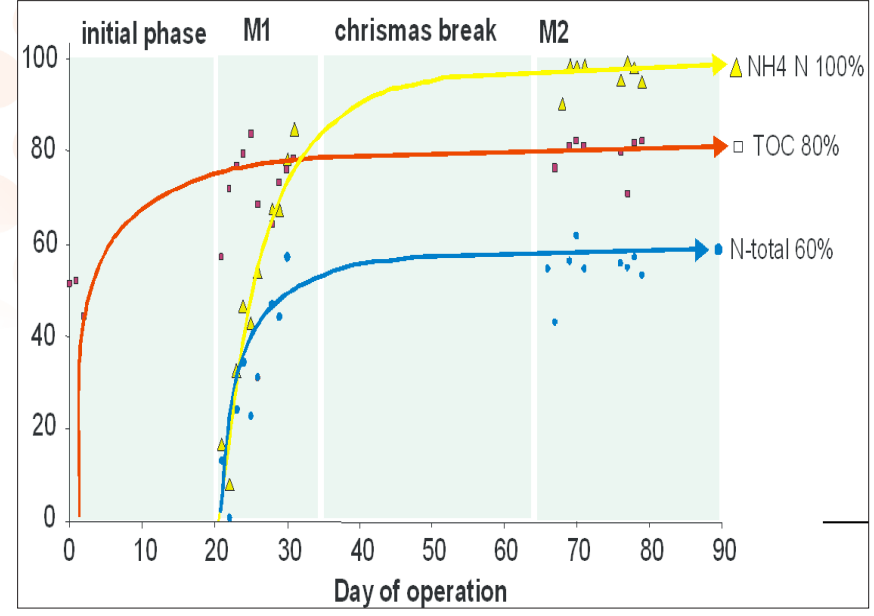

Figure 4: Reduction of TOC and N-Total during the operation phase

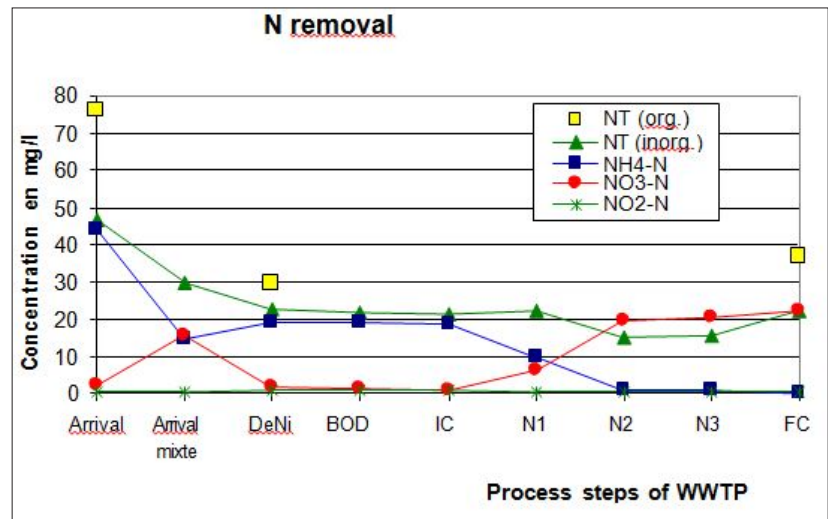

Figure 5: $\mathrm{N}$ removal in the Pilot plant stages

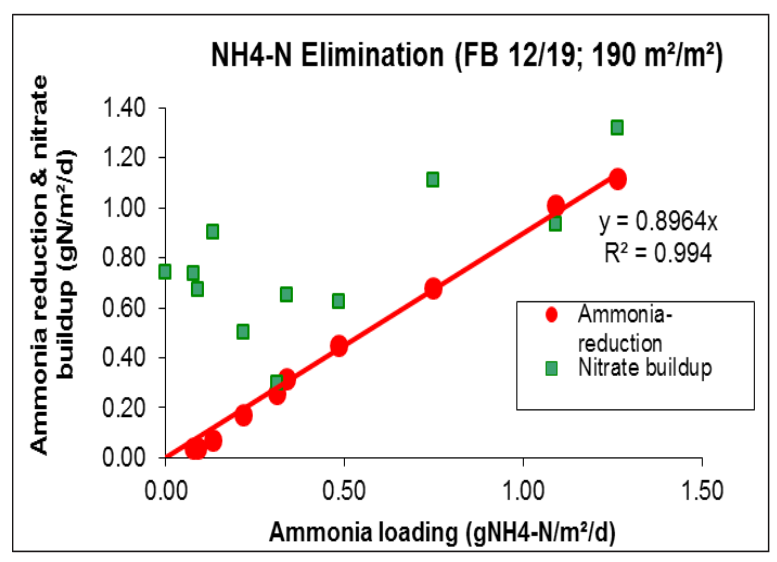

Figure 6: Ammonia-reduction and nitrate build-up in the nitrification reactor

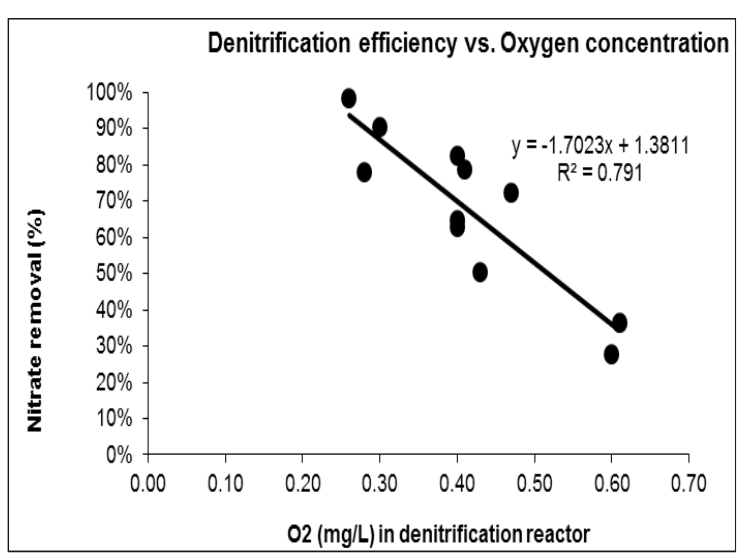

Figure 7: Denitrification vs. oxygen concentration. 


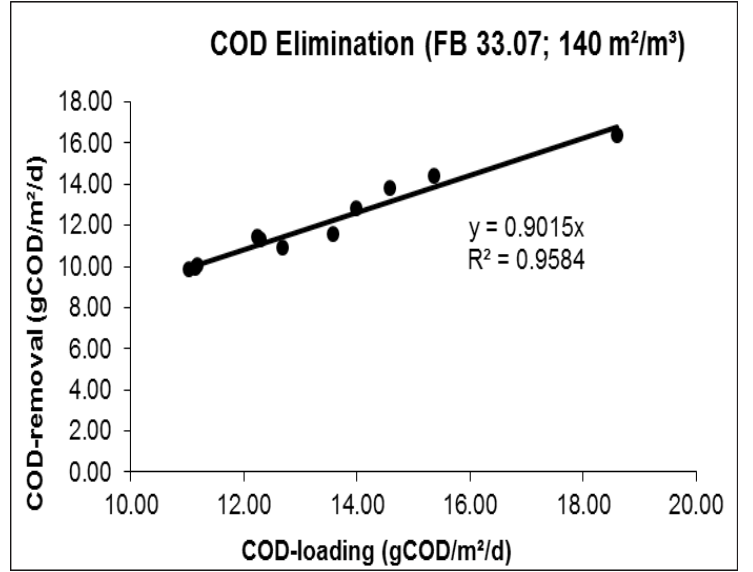

Figure 8: COD-loading rates vs. COD elimination per surface unit

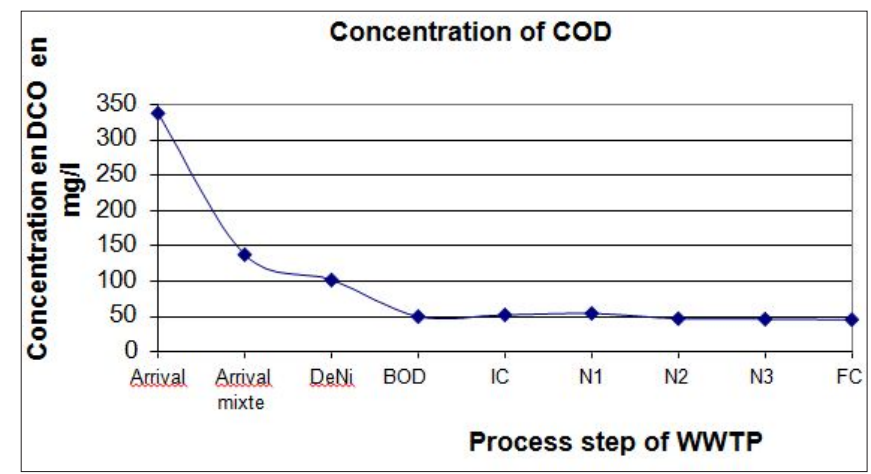

Figure 9: COD removal in the pilot WWTP.

\section{Novel process elements}

Besides on the combination of fixed and suspended biofilm technology, the WWTP shows some more novel and innovative features:

1. Heavy carriers: Random biofilm carriers with a specific density of $1.02 \mathrm{~kg} / \mathrm{L}$ are applied for the de-nitrification reactor. Carriers will sink to the reactor bottom when agitation is not applied. Gentle agitation was applied to enable substrate transport through the bulk of carriers, whereas strong agitation is applied for short periods in order to shear off excess sludge.

2. Air-flushed-carrier-screen: The moving bed biofilm carriers should be prevented from escaping the denitrification reactor. A $45^{\circ}$ tilted screen (mesh-size 8 $\mathrm{mm}$ ) is mounted on top of the barrier plate between denitrification and $\mathrm{C}$-elimination reactors. The screen will be flushed with air due to the aeration of the C-removal reactor. As the screen is located just below the water level, it is easily assessable for maintenance and inspection. The air washing avoids all mechanical stress to the carrier material.

3. Mixing device: The agitation of MBBR systems with propeller-shaped mixers may lead to the damage of carriers, the propeller itself, or both. Almost no theoretical approaches are known for application in moving bed systems. In the experimental setup a mixing device, which is usually applied in food processing industries, will be applied and tested.

4. Intermediate settling with tube settlers: Sludge will be withdrawn in an intermediate settler when heterogamous biomass growth has been completed. It is expected, that the subsequent autotrophic growth will thus be enhanced. On the other hand, less additional sludge is produced by nitrification and the final settling tank may become redundant. The disadvantage of an intermediate settler is the four-fold hydraulic load (correspondent to the recycle flow). This disadvantage is compensated by the application of tube settlers in the intermediate settling tank, which allows a smaller tank size.

\section{Economic aspect}

This study revealed that the use of submerged fixed-film for the aerobic reactor and moving bed for anaerobic denitrification stage can be a cost-effective system due to its low Operating cost (OPEX) and Capital Cost (CAPEX).

The comparison between the application of the above treatment concept and the activated sludge treatment system for the same 200 PE small unit shows reduction of about $50 \%$ of tanks volumes in the system by using the Biofilm concept taking into consideration using lamellar settler in the sedimentation stages.

Therefore, and according to the treatment evaluation, the application of Biofilm technologies by using a specific plastic media (Figure 2), showed a clear improvement in the system performance.

To have the clear figure about the saving Energy, Tank volume and also some other benefits by using the biofilm technologies and, the $2 \mathrm{~h} \mathrm{GmbH}$ above concept in addition of considering lamellar settler in the sedimentations stages, a below comparison between application of above system and activated sludge system for the same unit $200 \mathrm{P}$ in the MENA region. A reduction of about $50 \%$ in the tanks volumes using the Biofilm concept (Table2). In addition, the application of this concept saved more than $40 \%$ Tank size; $85 \%$ sealed groung; and up to $30 \%$ construction cost.

\begin{tabular}{|l|l|l|l|l|}
\hline & Activated sludge Tank $\left(\mathrm{m}^{3}\right)$ & Biofilm Tank $\left(\mathrm{m}^{3}\right)$ & Biofilm Media $\left(\mathrm{m}^{3}\right)$ & Biofilm Media (Type) \\
\hline Denitrification & 714 & 75 & 37.5 & BCN14 \\
\hline Carbon removal & & 127 & 80 & KVP623 \\
\hline Intern. Settling & & 143 & 30 & FS.41.84 \\
\hline Nitrification & 714 & 444 & 333 & KVP618 \\
\hline Final settling & 263 & 57 & 11 & FS41.50 \\
\hline
\end{tabular}

Table 2: Comparison between the activated sludge and compact-system design (biofilm Media application by $2 \mathrm{~h}$ GmbHGermany) 


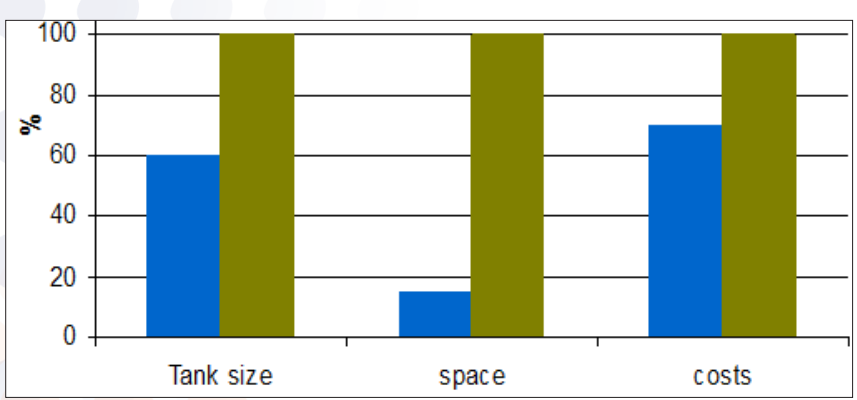

Figure 10: cost saving after instalition of $2 \mathrm{H} 2 \mathrm{~h} \mathrm{GmbH}$ concept (Moving bed in anerobic stage and Summerged fixed film in anerobic stage).

\section{Conclusions and Recommendation}

Biofilm system is recommended for both upgrading the existing and new implemented wastewater treatment plants. The advantages of biofilm applications can be summarized as follows:

1. Ability to phase-in additional capacity or improve performance by adding more media;

2. Additional biomass for treatment without increasing the solids loading on final clarifiers;

3. Higher-rate treatment processes are possible, thus allowing greater treatment in a smaller space;

4. Improved settling characteristics (reduced sludge volume index);

5. In periods of less loading, microorganisms which are settled on the fixed-bed capsulate themselves. That is how they can survive longer starvation phases without any damage. The only requirement is to have a minimum of oxygen in the water. If there is no accruing wastewater for longer period, the control system of the plant can be switched into holiday mode. This way the aeration of the fixed-bed is reduced to $10 \%$ of the normal electricity consumption. When getting back to normal operating conditions the original purification capacity is achieved in a few days by the fast reactivation of bacteria;

6. Fixed-bed plants work effectively without expensive separators and long settling time. The reason for that: the microorganisms come off from the surface of the fixed-bed in flakes with high specific weight. They settle afterwards easily in the secondary clarification. The result is optimal settling performance of the secondary treatment and little amount of solid content in the effluent of the plant.

However, experience in the operation of biofilm technologies shows that: Biofilm system applications faced several operations problems in the MENA region. This is related to the lack of experience in biofilm system operation. Some recommendations need to be taken into consideration when applying biofilm technologies for wastewater treatment as follows:

1. Appropriate \& effective pre-treatment system to remove fats, oils and grease to protect the biofilm and its specific surface area

2. An appropriate primary treatment is required to reduce high concentrations of BOD5, TSS in inflow, this protects the biofilm treatment capacity in the biological stage.

3. Researches demonstrate that biofilm technologies should be designed based on the surface area loading rate ( $\mathrm{g}$ $\mathrm{COD} / \mathrm{m} 2 \mathrm{~d}$ ), Media material, wastewater type.

4. An intermediate clarifier tank is useful to build between treatment stages to draw out the sludge produced and to keep the attached bacteria working in its full capacity.

5. The applications of wastewater treatment by biofilm technologies show a cost-effective implementation to improve treatment efficiency \& high quality effluent

\section{Acknowledgement}

This work was financially supported by a Grant from the German Ministry of Research and Education (BMBF) within the framework of project "export oriented research and development for waste water treatment".

\section{References}

1. Wilderer, P.A. (2005) "A unique challenge and chance for water engineers. Water Sci Technol". UN water action decade: 2005, 51, 99-107. [PubMed].

2. Anil, R.; Neera, A.L. (2016) "Modified Septic Tank Treatment System”. Proc. Technol. 2016, 24, 240-247. [CrossRef].

3. Boltz, J. P.; La Motta, E. J. (2007). "The Kinetics of Particulate Organic Matter Removal as a Response to Bio flocculation in Aerobic Biofilm Reactors". Water Environ. Res., 79, 725.

4. IPCC (2006). "IPCC Guidelines for National Greenhouse gas inventories.

5. Bratbak, G., \& Dundas, I. (1984). Bacterial dry matter content and biomass estimations. Applied and environmental microbiology, 48(4), 755-757.

6. Nouvion, Block \& Faup. (1987). Effect of biomass quantity and activity on TOC removal in a fixed-bed reactor. Wat. Res. 21, 35-40.

7. Deibel, N. (2003). "Develop a Defense Against Biofilms". Food Safety Magazine <http://www.biofilm.montana.edu/ biofilm-basics.html $>$ Accessed 18 Jan. 2012.

8. Metcalf.; Eddy. (2003). "Wastewater Engineering: Treatment and Reuse", 4th ed., McGraw-Hill, Boston, Massochusetts, pp. 602-607.

9. Shareef, Noama. (2019). "Innovation Technologies in Wastewater Treatment: A Cost-Effective Solution”. Waste Management Book, springer ISBN 978-3-030-18350-9. P 30-37 July 2020.

10. APHA (1995). Standard Method for examination of water and wastewater. Water Environment Federation. 19th edition. American Public Health Association, Washington DC, USA.

11. Brix, H. \& Arias, C. A. (2005b). The use of vertical flow constructed wetlands for on-site treatment of domestic wastewater: New Danish guidelines. Ecological Engineering 25, 491-500.

12. Mazumder, D.; Roy, B. (2000). "Low cost options for treatment and reuse of municipal wastewater". Indian $J$. Environ. Prot. 2000, 20, 529-532. 
13. Sharma, M.K.; Kazmi, A.A. (2015). "Anaerobic onsite treatment of black water using filter-based packaged system as an alternative of conventional septic tank". Ecol. Eng. 2015, 75, 457-461. [CrossRef]

Copyright: $\odot 2021$ Noama Shareef. This is an open-access article distributed under the terms of the Creative Commons Attribution License, which permits unrestricted use, distribution, and reproduction in anymedium, provided the original author and source are credited. 